\title{
Plasma Calprotectin Levels in Patients Suffering from Acute Pancreatitis
}

\author{
Antonio Carroccio - Pasquale Rocco • \\ Pier Giorgio Rabitti • Lidia Di Prima • \\ Giovanni Battista Forte - Angelo B. Cefalù • \\ Franco Pisello • Girolamo Geraci • Generoso Uomo
}

Received: 30 June 2005 / Accepted: 22 September 2005

(C) Springer Science+Business Media, Inc. 2006

\begin{abstract}
Calprotectin (Cal) concentration is elevated in acute inflammatory reactions and its increase in the plasma suggests a diagnostic potential for $\mathrm{Cal}$ assay. This study aimed (a) to evaluate the Cal plasma levels in patients suffering from acute pancreatitis (AP) and (b) to assess whether early assay of Cal plasma levels can be helpful in assessment of the severity of AP. Forty-six consecutive patients, median age 45 years, suffering from a first attack of AP were recruited at two medical centers. Data collected on admission included age, sex, delay between pain onset and admission, and Glasgow score. A severe outcome was defined according to the Atlanta criteria. AP was defined as edematous or necrotic according to the $\mathrm{CT}$ findings. Plasma $\mathrm{Cal}$ and serum $\mathrm{C}$ reactive protein (CRP) were assayed in all patients within the first $24 \mathrm{hr}$ after hospitalization. Sixty subjects suffering from blood hypertension were recruited as controls. Plasma Cal was measured by a commercial ELISA system. In all AP patients and in none of the controls, plasma Cal concentration was higher than the normal limit. Cal values in AP pa-
\end{abstract}

A. Carroccio $(\varangle) \cdot$ L. Di Prima $\cdot$ A. B. Cefalù

Medicina Interna, Policlinico di Palermo,

via del Vespro 141,

90127 Palermo, Italy

e-mail: acarroccio@hotmail.com

P. Rocco · G. B. Forte

Gastroenterology Division, Ospedale Civile di Caserta,

Caserta, Italy

P. Rabitti · G. Uomo

Internal Medicine, "Cardarelli" Hospital,

Naples, Italy

F. Pisello · G. Geraci

Surgery Department, University Hospital of Palermo,

Palermo, Italy tients were significantly higher than in controls $(P<0.0001)$. There was not a statistically significant difference in Cal values between patients with severe and patients with mild AP. Plasma Cal values did not differ in necrotizing and edematous AP. During the follow-up plasma Cal was reassayed in six of the patients with abdominal fluid collection and the values were higher in the two patients with infected necrosis. We conclude that plasma $\mathrm{Cal}$ is elevated in patients with AP but it is not a useful marker for early prediction of pancreatitis severity. Further studies could evaluate its usefulness in pancreatic infected necrosis.

Keywords Calprotectin - Acute pancreatits $\cdot$ Pancreatic infected necrosis $\cdot$ Prognosis

\section{Introduction}

Calprotectin $(\mathrm{Cal})$ is a calcium binding protein belonging to the S-100 protein family and derived predominantly from neutrophils and monocytes [1,2]. Various biological functions have been ascribed to $\mathrm{Cal}$, including regulation in the inflammatory process [3] and antimicrobial activity [4]. Cal concentration is elevated in acute inflammatory reactions, and in some instances a correlation between $\mathrm{Cal}$ and other inflammation paramenters such as $\mathrm{C}$ reactive protein (CRP), erythrocyte sedimentation rate, and neutrophil granulocyte count has been shown [5]. As Cal is found in all tissues of the human body, its assessment in several fluids could distinguish between normal and pathological conditions [2]. For instance, an elevated Cal concentration in stools is considered a marker of intestinal neoplasias [6] or inflammatory bowel diseases [7] and helps to distinguish between organic causes of chronic diarrhea and irritable bowel syndrome [8]. 
An increased concentration of $\mathrm{Cal}$ in the plasma has been found in several organic diseases and suggests a diagnostic potential for Cal assay [2]. Despite these very promising data, no studies on the plasma Cal concentration in patients with acute pancreatits (AP) have been performed to date.

Aims of the present study were (a) to evaluate Cal plasma levels in patients suffering from AP and (b) to investigate whether early assay of Cal plasma levels could be helpful in assessment of the severity of AP.

\section{Patients and methods}

Forty-six consecutive patients ( 25 males), median age 45 years (range, 19-75 years), suffering from a first attack of AP were recruited at two medical centers, between January and December 2002. The diagnosis was based on the association of clinical symptoms, serum lipase and amylase increase, and characteristic computed tomographic (CT) findings. Patients with prior episodes of unexplained abdominal pain or with signs of chronic pancreatitis were excluded. Thirty-four patients had biliary AP, diagnosed on ultrasound or CT examinations; five had alcohol-induced AP, as they reported a daily intake of $>100 \mathrm{~g}$ pure alcohol and an alcohol excess immediately before the acute attack; and in seven cases the etiology remained unknown (idiopathic AP). Data collected on admission included age, sex, delay from pain onset to admission, and Glasgow score [9]. A severe outcome was defined according to the Atlanta criteria [10]. AP was defined as edematous or necrotic according to the contrast-enhanced CT findings. Serum amylase and lipase and plasma $\mathrm{Cal}$ were assayed in all patients within the first $24 \mathrm{hr}$ after hospitalisation; all the biochemical markers included in the Glasgow score and the CRP concentration were analyzed on the same blood sample.

Sixty subjects suffering from blood hypertension, sex and age matched with the study group, without inflammatory diseases or a history of acohol abuse, and with normal serum amylase values, were recruited as controls for plasma Cal values.

All subjects gave their informed consent to all procedures described in this study. The study protocol was approved by the Ethics Committee of the University Hospital of Palermo.

Plasma calprotectin determination

Blood samples were drawn into EDTA tubes and centrifuged at $2000 \mathrm{rpm}$ for $15 \mathrm{~min}$. Laboratory personnel unaware of the clinical diagnoses or details of the patients' clinical histories assayed plasma calprotectin. The concentrations were measured using a commercial ELISA system (Calprest; Eurospital, Trieste, Italy) based on polyclonal antibodies against calprotectin. Two $100-\mu 1$ plasma aliquots from a sin- gle sample from each participant were assayed, and the mean of the two measurements was recorded. Threshold values supplied by the manufacturer (normal values, $0.3-1.6 \mu \mathrm{g} / \mathrm{ml}$ ) were considered for statistical analysis. The intra-assay coefficient of variation (CV) for plasma Cal was $3.8 \%$ at a mean (SD) of $1.1(0.2)(n=20)$, and the interassay $\mathrm{CV}$ was $8 \%$. The physicians who made the final evaluation of the $\mathrm{AP}$ severity were unaware of the $\mathrm{Cal}$ results throughout the study.

Statistical analysis

For the intergroup Cal concentration comparison, we used Mann-Whitney $U$ test or Student's $t$ test according to whether there was a non-Gaussian or Gaussian distribution of the data. The Spearman $r$ correlation coefficient was used to correlate plasma Cal concentration with CRP and Glasgow score values.

\section{Results}

In all AP patients plasma Cal concentration was higher than the normal limit: the values ranged between 1.7 and $6.3 \mu \mathrm{g} / \mathrm{ml}$. On the contary, none of the control subjects had values above the reference limit (Fig. 1). Plasma Cal values in AP patients were significantly higher than in controls: mean values (SD) were $5.3(1.9) \mu \mathrm{g} / \mathrm{ml}$ in AP and $1.0(0.3)$ $\mu \mathrm{g} / \mathrm{ml}$ in controls $(P<0.0001)$. In patients with AP there was a trend toward higher plasma $\mathrm{Cal}$ values in cases with alcoholic etiology than in those due to gallstones (mean values $\pm \mathrm{SD}, 5.6+1.2$ versus $5.1 \pm 1.0 \mu \mathrm{g} / \mathrm{ml}$; difference not statistically significant).

According to the Atlanta criteria for AP severity, 12 patients $(26 \%)$ had severe AP and $34(74 \%)$ had mild AP. Figure 2 shows the individual and median plasma Cal values in patients with severe and mild AP; there was a trend toward higher plasma $\mathrm{Cal}$ values in patients with severe pancreatitis, but the difference was not statistically significant in comparison with values observed in mild AP. Serum CRP concentration was higher in patients with severe AP than in those with a mild form, and this difference was statistically significant: mean (SD) values were $18.5(4.3) \mathrm{mg} / \mathrm{L}$ in severe AP and $3.9(2.9) \mathrm{mg} / \mathrm{dl}$ in mild forms $(P<0.0001)$. Also, the Glasgow score was significantly higher in patients with severe than in those with mild $\operatorname{AP}(P=0.04)$. No statistically significant correlation was found between plasma $\mathrm{Cal}$ values and CRP concentration or Glasgow score.

Contrast-enhanced CT revealed necrotizing pancreatitis in 11 patients and edematous AP in the others; plasma Cal values, although higher in the subjects with necrosis, did not differ according to the presence or absence of the necrosis. Further CT evaluation showed the development of a 


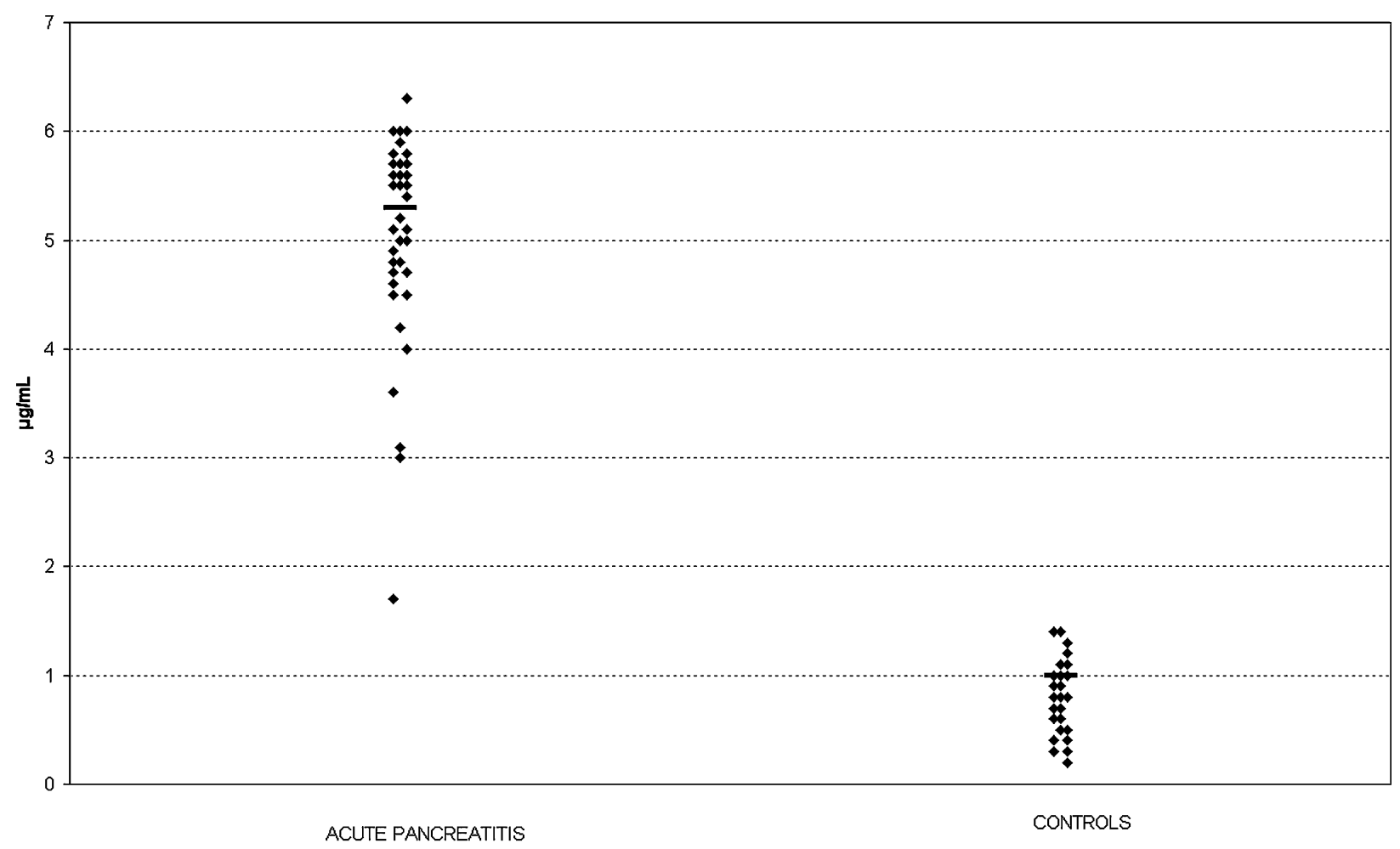

Fig. 1 Individual and mean (Barr) values of plasma calprotectin in patients with acute pancreatitis and in controls

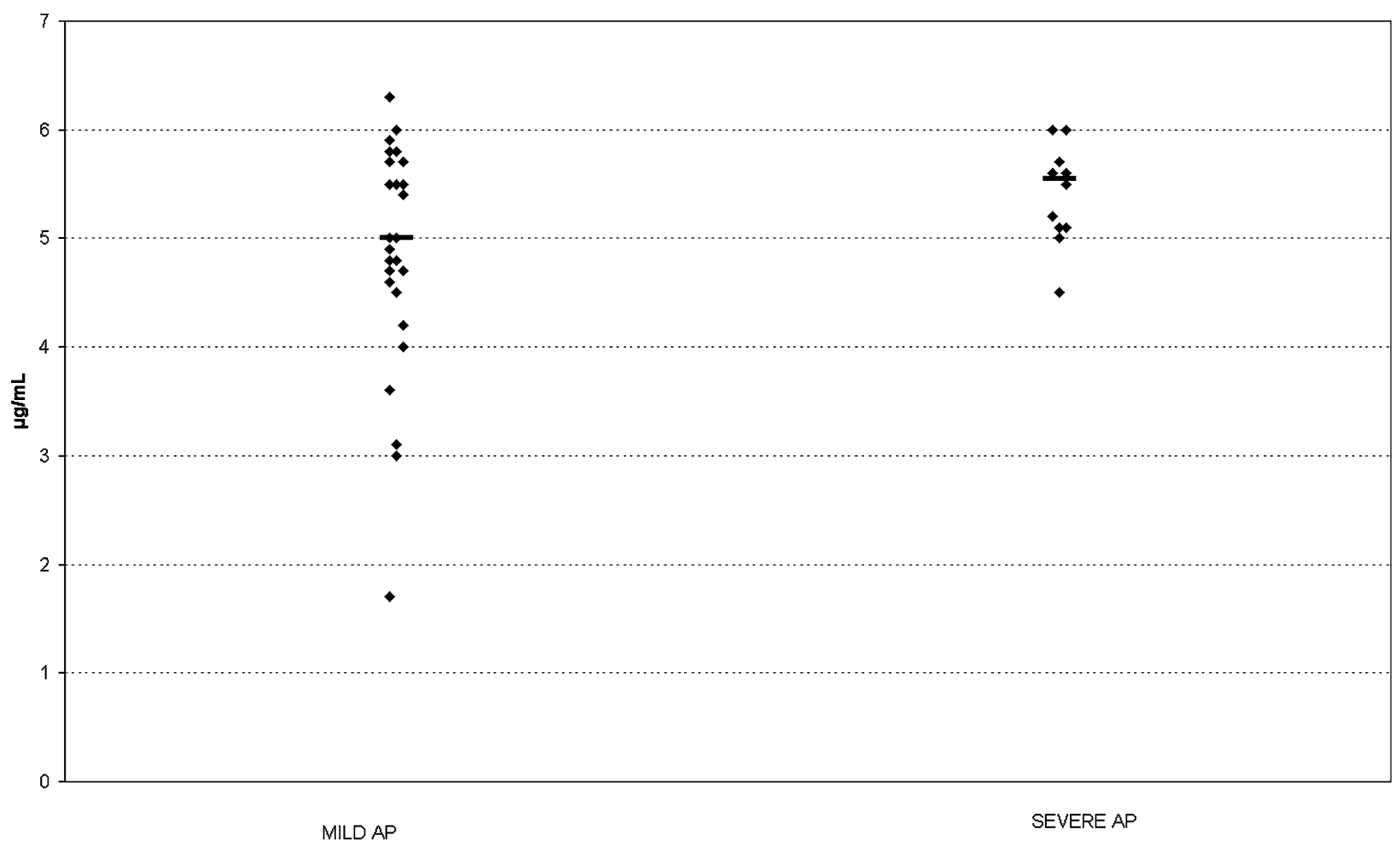

Fig. 2 Individual and mean (Barr) values of plasma calprotectin in patients with acute pancreatitis, divided according to the Atlanta criteria for severity of pancreatitis 
pancreatic pseudocyst in five patients; plasma Cal values at hospitalisation did not differ between patients who developed a pseudocyst in comparison with all other AP patients.

During the hospital stay, pancreatic infected necrosis was found in two patients; at the moment of the hospitalization, the plasma Cal values of these two patients did not differ from those of all other AP patients. However, between the 6th and the10th days of hospitalization, plasma $\mathrm{Cal}$ was reassayed in six of the patients with abdominal fluid collection and suspected infected necrosis, including the two subjects who really had infected necrosis. The latter subjects had plasma Cal values higher than those of the others: 6.1 and $7.2 \mathrm{mg} / \mathrm{dl}$ in the patients with infected necrosis versus $3.2,2.3,1.8$, and $1.8 \mathrm{mg} / \mathrm{dl}$ in the patients with fluid collection without infection.

Only two patients underwent surgical treatment, both for infected necrosis (necrosectomy with a left sided resection); one of them died in the first week after surgery.

\section{Discussion}

Plasma Cal is an interesting marker of inflammation. Previous studies demonstrated its usefulness in active rheumatic disease [5, 11], cystic fibrosis [12], pulmonary infections [13], and several other diseases [2]. In all cases the differences between normal and pathological levels suggested a diagnostic potential for $\mathrm{Cal}$ assay. Although $\mathrm{Cal}$ is mainly produced by neutrophils and monocytes, it is found in cells in all part of the body and its presence has also been demonstrated in pancreatic cells [14]. Despite these promising prospectives, no previous studies have evaluated the usefulnes of plasma $\mathrm{Cal}$ assay in patients with AP.

Our results demonstrate that plasma $\mathrm{Cal}$ is elevated in all patients with AP and in none of the controls; however, as we recruited control subjects without signs of acute inflammation, the high specificity of $\mathrm{Cal}$ in identifying AP patients cannot be considered a "real" result, and, on the other hand, serum amylase and lipase assays are considered sufficiently specific to confirm the clinical suspicion of AP. A more realistic goal in AP patients is the prediction of severity [15, 16]; in fact, early assessment of severity in AP can permit the selection of those patients who will benefit from a more intensive and early treatment with antibiotics [17] or antiprotease drugs [18], although this last point is still being debated [19, 20]. Unfortunately, in this respect, plasma Cal assay did not offer any advantage. Although there was a trend for higher Cal values in severe versus mild AP and in necrotizing versus edematous AP, the overlap of values between the groups did not permit any prediction of the course of the disease. On the contrary, serum CRP concentration confirmed its usefulness in distinguishing between severe and mild forms of AP [21, 22]. Obviously, it remains to verify whether a later assay of plasma $\mathrm{Cal}$, or its monitoring during the hospital stay, could indicate the severity of AP, but even if so, a late prediction of AP severity is less important. However, the last result of the present study could be reevaluated in future researches: the use of plasma $\mathrm{Cal}$ as a marker of pancreatic infected necrosis. In fact, when plasma Cal was assayed in six patients with suspected infected necrosis, the highest values were recorded in the two patients who really suffered from infected necrosis.

In conclusion, we have shown that plasma $\mathrm{Cal}$ is elevated in patients with AP but it is not a useful marker for early prediction of the severity of pancreatitis. Further studies could evaluate its usefulness in patients who will develop infection of pancreatic necrosis, which still remains an unforeseeable event in the course of the disease.

Acknowledgments Preliminary data from this study were reported at the XXVII Meeting of the Italian Society for Pancreatic Study (AISP; Catania, Italy, September 18-20, 2003) and published as an abstract in Digestive and Liver Disease (35:S1-S12, 2003) and reported at the III Meeting of the Mediterranean Societies of Pancreatology (Santiago de Compostela, Spain, December 11-13, 2003) and published as abstract in Pancreatology (3:467-468, 2003).

\section{References}

1. Fagerhol MK (1996) Nomenclature for proteins: Is calprotectin a proper name for the elusive myelomonocytic protein? J Clin Pathol Mol Pathol 49:M74-M79

2. Johne B, Fagerhol MK, Lyberg T, et al. (1997) Functional and clinical aspects of the myelomonocyte protein calprotectin. Mol Pathol 50:113-123

3. Brun JG, Ulvestad E, Fagerhol MK, Jonsson R (1994) Effects of human calprotectin on in vitro immunoglobulin synthesis. Scand J Immunol 40:675-680

4. Steinbakk M, Naess-Andresen CF, Lingaas E, Dale I, Brandtzeg P, Fagerhol MK (1990) Antimicrobial actions of calcium binding leucocyte L1 protein, calprotectin. Lancet 336:763-765

5. Berntzen HB, Olmez U, Fagerhol MK, Munthe E (1991) The L1 protein as a new indicator of inflammatory activity in patients with juvenile rheumatoid arthritis. J Rheumatol 18:1338-1339

6. Kronborg O, Ugstad M, Fuglerud P, et al. (2000) Fecal calprotectin levels in a risk population for colorectal neoplasia. Gut 46:795800

7. Tibble J, Teahon K, Thjodleifsson B, et al. (2000) A simple method for assessing intestinal inflammation in Crohn's disease. Gut 47:506-513

8. Carroccio A, Iacono G, Cottone M, et al. (2003) Diagnostic accuracy of fecal calprotectin assay in distinguishing organic causes of chronic diarrhea from irritable bowel syndrome: a prospective study in adults and children. Clin Chem 49(6):861-867

9. Imrie CW, Benjamin IS, Ferguson JC, et al. (1978) A single-center double-blind trial of Trasylol therapy in primary acute pancreatitis. Br J Surg 65:337-341

10. Bradley EL (1993) A clinically based classification system for acute pancreatitis. Arch Surg 128:586-590

11. Haga HJ, Brun JG, Berntzen HB, Cervera R, Khamashta M, Huges GRV (1993) Calprotectin in patients with systemic lupus erythematosous: relation to clinical and laboratory parameters of disease activity. Lupus 2:47-50 
12. Golden BE, Clohessy PA, Russell G, Fagerhol MK (1996) Calprotectin as a marker of inflammation in cystic fibrosis. Arch Dis Child 74:136-139

13. Stockley RA, Dale I, Hill SL, Fagerhol MK (1984) Relationship of neutrophil cytoplasmic protein (L1) to acute and chronic lung disease. Scand J Clin Lab Invest 44:629-634

14. Fanjul M, Renaud W, Merten M, Guycrotte O, Hollande E, Figarella C (1995) Presence of MRP8 and MRP14 in pancreatic cells lines: differential expression and localization in CFPAC-1 cells. Am J Physiol Cell Physiol 37:C1241-C1251

15. Appelros S, Petersson U, Toh S, Johnson C, Borgstrom A (2001) Activation peptide of carboxypeptidase $\mathrm{B}$ and anionic trypsinogen as early predictors of severity of acute pancreatitis. Br J Surg 88:216-221

16. Sandberg AA, Borgstrom A (2002) Early prediction of severity in acute pancreatitis. Is it possible? JOP J Pancreas (Online) 3:116125
17. Sainio V, Kemppainen E, Puolakkainen P, et al. (1995) Early antibiotic treatment in acute necrotising pancreatitis. Lancet 346:663667

18. Messori A, Rampazzo R, Scrocaro G, et al. (1995) Effectiveness of gabexate mesilate in acute pancreatitis. A meta-analysis. Dig Dis Sci 40:734-738

19. Andriulli A, Leandro G, Clemente R, et al. (1998) Meta-analysis of somatostatin, octreotide and gabexate mesilate in the therapy of acute pancreatitis. Aliment Pharmacol Ther 12:237-245

20. Cavallini G, Frulloni L (2001) Somatostatin and octreotide in acute pancreatitis: the never-ending story. Dig Liv Dis 33:192-201

21. Wilson C, Heads A, Shenkin A, Imrie CW (1989) C-reactive protein, antiproteases and complement factors as objective markers of severity in acute pancreatitis. Br J Surg 76:177-181

22. Neoptolemos JP, Kemppainen EA, Mayer JM, et al. (2000) Early prediction of severity in acute pancreatitis by urinary trypsinogen activation peptide: a multicentre study. Lancet 355:1955-1960 